\title{
What Can We Learn About Educational Project Management in Times of Covid-19?
}

\author{
Hassana MAHFOUD*
}

\begin{tabular}{l} 
ARTICLE INFO \\
\hline Article History: \\
Received 01.04.2020 \\
Received in revised form \\
02.12 .2020 \\
Accepted \\
Available online 01.04 .2021
\end{tabular}

\begin{abstract}
In the actual covid-19 crisis, Moroccan universities have been obliged to convert face-to-face education to online education context. This situation is much more challenging for students who are appealed to work collaboratively on their final project as well as for teachers who must monitor the project progress and students' performance. This paper presents an experiment report of initial implementation of agile strategy in remote project management of undergraduate students. The study is approached from two point of view: communication and collaboration; data centralization and efficient monitoring. The discussion is based on student's online activity analysis and structured survey of students' perception on the applied method. The results reveal that the integration of the agile strategy has a significant positive impact on students' performance in online project management and offers an interesting tool for teachers supervising project teamwork.
\end{abstract}

(C) IJERE. All rights reserved

Keywords:
Covid19, remote project management, agile strategy, educational context, collaborative learning

Keywords:
Covid19, remote project management, agile strategy, educational context, collaborative learning

\section{INTRODUCTION}

Undergraduate computer engineering students are engaged in diverse projects during their studies, as project-based learning is the fundamental component of their curriculum. The main complexity of these projects lies in broad scope, short duration and large size of teams. To reduce the complexity of their projects, it's supposed to use project management principles, traditionally the so-called "Waterfall" framework. Based on this approach, students should apply reductionism: breaking up the problem into tasks, develop a basic timeline and assign tasks to group members. The project is done following a sequential process involving a cascade of phases, often represented Gantt charts. One of the clear disadvantage of this method is that it is fairly static and rigid: enclosing the project from the start in choices that are fairly strictly defined and not very adaptable during development (Bass et al., 2016). In addition, regular meetings between team members and the project supervisor should be taken place to discuss project progress, which is usually unpredictable because of the unclear definition of roles and responsibilities. Besides, it's mostly difficult for teachers to have a clear idea about students' involvement in the project to assess teamwork organization and collaboration.

Project management in times of Covid-19 pandemic can appear as a real challenge, especially if the university has been compelled to experiment with remote work, without preliminary arrangements (Almathkoori, Bouchareb \& Flores-Tena, 2020 ;Camélia Docquin, 2020; Makhzoum \& Jabbour, 2020; Rabbi, Smita \& Mohammad 2020). It may also look challenging in the case of supervising students projects with the characteristics discussed previously. Indeed, the ongoing crisis is a welcome reality check, as it zooms all those small issues and inefficiencies, paving the way for more efficient project management practices learning. In this paper, we discuss the keys to successful remote project management learning. The subject is approached along two axes: communication and collaboration, Data centralization and efficient monitoring.

\section{1) Communication and collaboration}

Team work and collaboration is one of the key skills that students must acquire to meet project management learning objectives. However, just proposing team work doesn't guarantee effective collaboration (Miller \& Hadwin, 2015), which surpasses the notion of grouping students together to work on a project and requires that students handle complex skills such as commitment, time management, affecting different roles and responsibilities, planning, and taking into account other views (Noguera et al., 2018). Students' collaboration becomes more challenging when they have to manage remotely a project.

\footnotetext{
* h.mahfoud@uca.ma; orcid.org/0000-0002-2388-0886; High School of Technology Safi, Cadi Ayyad University, Morocco.
} 
Performing an online collaborative project, students may feel discouraged due to communication difficulties and an unjust commitment among project team members.

Thus, alternative strategies are needed to help project teams enhance their collaboration skills, organize group work and increase teamwork satisfaction. The agile method is a well-known project management method that points to adjust teamwork processes. It varies from traditional approaches to project management as it is distinguished by a high adaptability to change: there is a continuous decision-making process based on oncoming needs and demands that are incorporated following a regular iterative reviews instead of a pre-established structured process: Besides, the agile method goes beyond the hierarchical topdown "Waterfall" framework and gives teams a predominant role by promoting an efficient roles allocation, encouraging frequent communication between team members and customers and splitting the work into tasks and regular deliveries (Noguera et al., 2018).

The agile approach especially that based on Scrum has been increasingly incorporated in higher education and collaborative research (Hidalgo, 2019; Kropp et al., 2016). In this context, eduScrum guide is one of the proposed approaches (Sutherland, 2020) that is a valuable to agile learning as it describes how the agile method can be transferred to face-to-face education in practice. However, it needs some adjustments to adapt the Eduagile framework to the e-learning context, in which there are no presential class sessions and no regular synchronous meetings. Previous agile-based learning experiences have proven the positive impact on project management and teamwork regulation: As example,(Kropp et al., 2016; Naik \& Jenkins, 2019; Noguera et al., 2018; Parsons et al., 2019)'s results indicate that agile strategies are useful for improving students' online project management and collaboration. Effectively, within the education context, agile strategies provides some advantages over traditional project management techniques like Transparency in teamwork as frequent meetings expose any weaknesses in contributions by team members, and project status understanding since frequent meetings provide all team members with a granular understanding of the status of the project (Bass et al., 2016; Maria et al., 2015).

\section{2) Data centralization and efficient monitoring}

In remote educational student project, especially in the current lockdown context, the team is not colocated, and often working at different times. Additionally, an agile project produces incrementally new knowhow and new knowledge. Each team member works on different document, so the primary need is to be able to collect and synchronize all these data. So there is no other option than to centralize the information (communication, work sheets, reports, documents ...). Without proper online collaboration tools, distributed student teams would not be feasible (Kropp et al., 2016), and in default of a centralized information system, there can no longer be proper remote agile project management (Camélia Docquin, 2020).

Opportunely, there are numerous online collaboration tools that can help to circumvent the impediments in "distributed" student teams. (Hidalgo, 2019; Kropp et al., 2016) presented some of these tools that simplify collaboration among students and make progress visible for the coach by Keeping everything in a shared location. For example, Trello board tool ensures all team members know what they're responsible for and what they need to work on. Besides, just like with data centralization, the remote project management context offer us to monitor project status more closely. (Kropp et al., 2016) discusses how online collaboration tools allow to the professor to coach and steer student projects and, that software engineering education benefits significantly by embracing the modern collaboration tools the Internet has made available. Indeed, without a data centralization tool, the project supervisor shouldn't be able to achieve efficient monitoring and reporting. The centralized system and monitoring process should be synchronized so that we get real time information about the project progress.

\section{LEARNING FROM PRACTICE}

\section{1) Method}

This case study utilizes two approaches: student's online activity qualitative analysis and structured survey. The study involved 85 undergraduate computer engineering students, aged between 19 and 21, implying $58 \%$ of males and $42 \%$ of females, and split on ten team working each on a different project. The 
online activity analysis involved group interactions on the digital Kanban tool Trello (Trello.com). This webbased project management app, is used as the main interface for coordination and knowledge sharing between project team members. A five month period of observation of various student activities from Trello boards enabled the understanding of patterns of interaction between levels of activity and types of interaction. The student's perception of the usefulness of the agile strategy to complete their projects was measured through a survey comprising 10 items covering: agile strategy for communication and collaboration, data centralization and efficient monitoring (Figure 1). The respondents sort the statements on a scale of four stars ranging from "not at all" to "a lot". This survey was given at the end of 2020 second semester and was completed anonymously online.

Figure 1: Agile project management survey

1. Do you believe that the distribution of roles of Scrum Team are helpful for group dynamics and distributing responsibilities?*

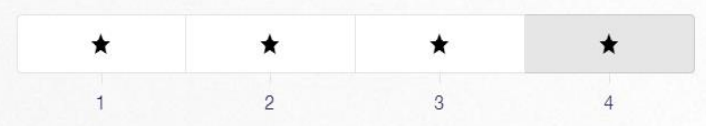

2. In your opinion, have the monitoring meetings been useful for work coordination and for anticipating deviations throughout the planning?*

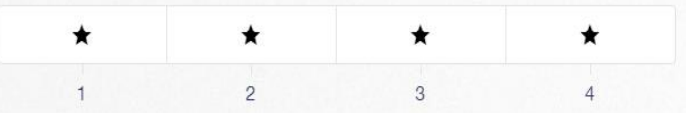

3. Do you believe that the agile methodology helped simplify teamwork organisation?*

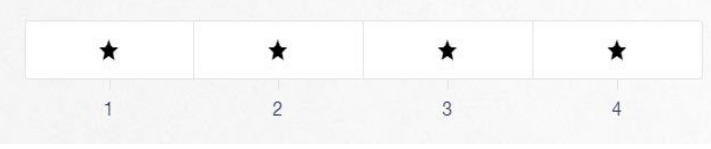

7. Do you think that the agile methodology has facilitated your project management this year?*

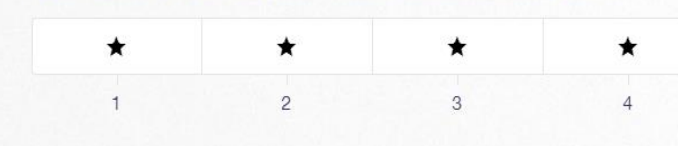

8. Do you believe that splitting the work into cycles is helpful for project development?*

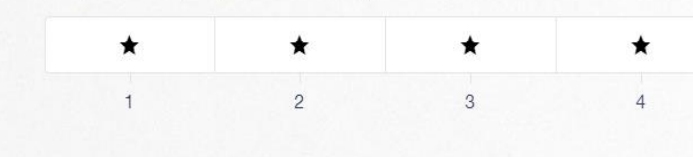

9. In your opinion, has the agile methodology been useful for completing the project?*

$\begin{array}{ccccc}\star & \star & \star & \star \\ 1 & 2 & 3 & 4\end{array}$

4. Do you think that Trello web based application helped to organize and centralize project data?*

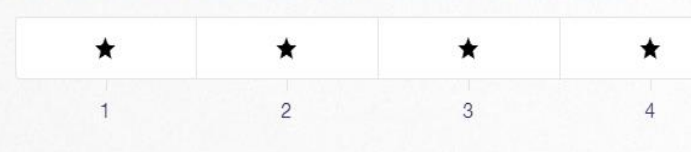

5. Do you think that Trello web based application helped tracking team project activities?*

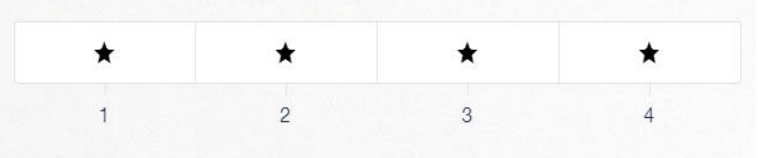

6. In your opinion, has the agile methodology been useful for monitoring the project progress?*

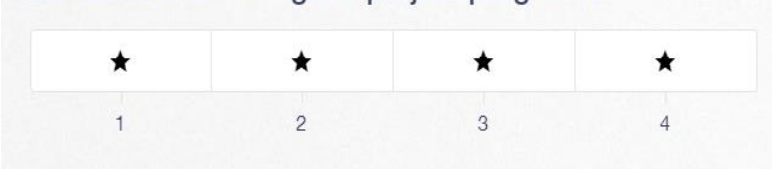

10. Do you believe that you will be able to transfer the agile methodology to other contexts in your life (professional, academic or personal)?*

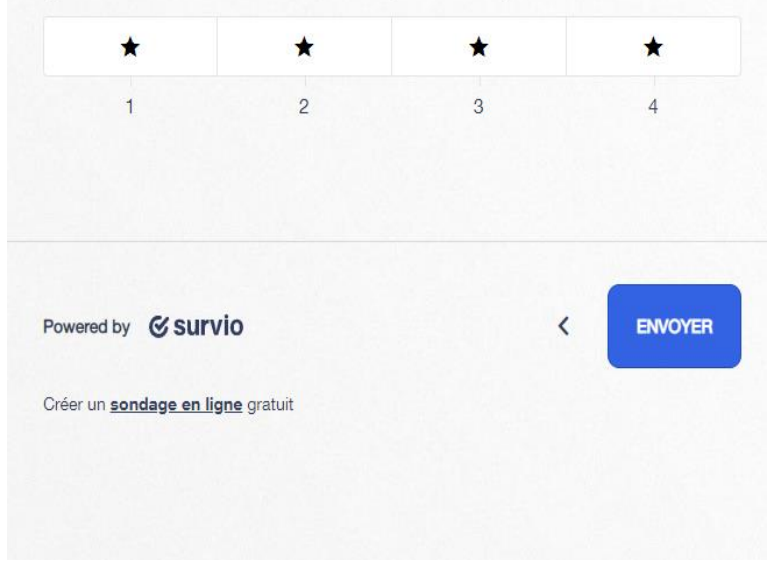




\section{2) Results and analysis}

The work process of each monitored project was divided into 3-5 sprit (depending on the complexity of the project) that last one to two week each. Teams created a list of tasks per each sprint (sprint backlog) and used Trello too for managing and scheduling them. The development of the project was reviewed iteratively through regular online meetings during and at the end of each sprit. Continuous formative e-feedback was provided and modifications are addressed in a short time to ensure on-time delivery.

Figure 2 shows some screenshots of the real work performed by a sample of project teams. As it is illustrated in the screenshots, the features available in Trello such boards, lists and cards enable the organization and progress tracking of projects in a flexible and engaging way. Furthermore, using a visualization tool like Trello help teams to visualize the project flow and react on time to contingencies. It allows integration of documents and produced knowledge into the workflow with synchronization across all devices and sites. Comparing the most active project team's boards in Trello and analyzing the different levels of engagement with the tool, revealed that the applied strategy was perceived as useful to have a quick overview of what is happening, and to understand the real-time project progress.

Figure 2: Screenshots of the work performed by some teams' boards during the project.
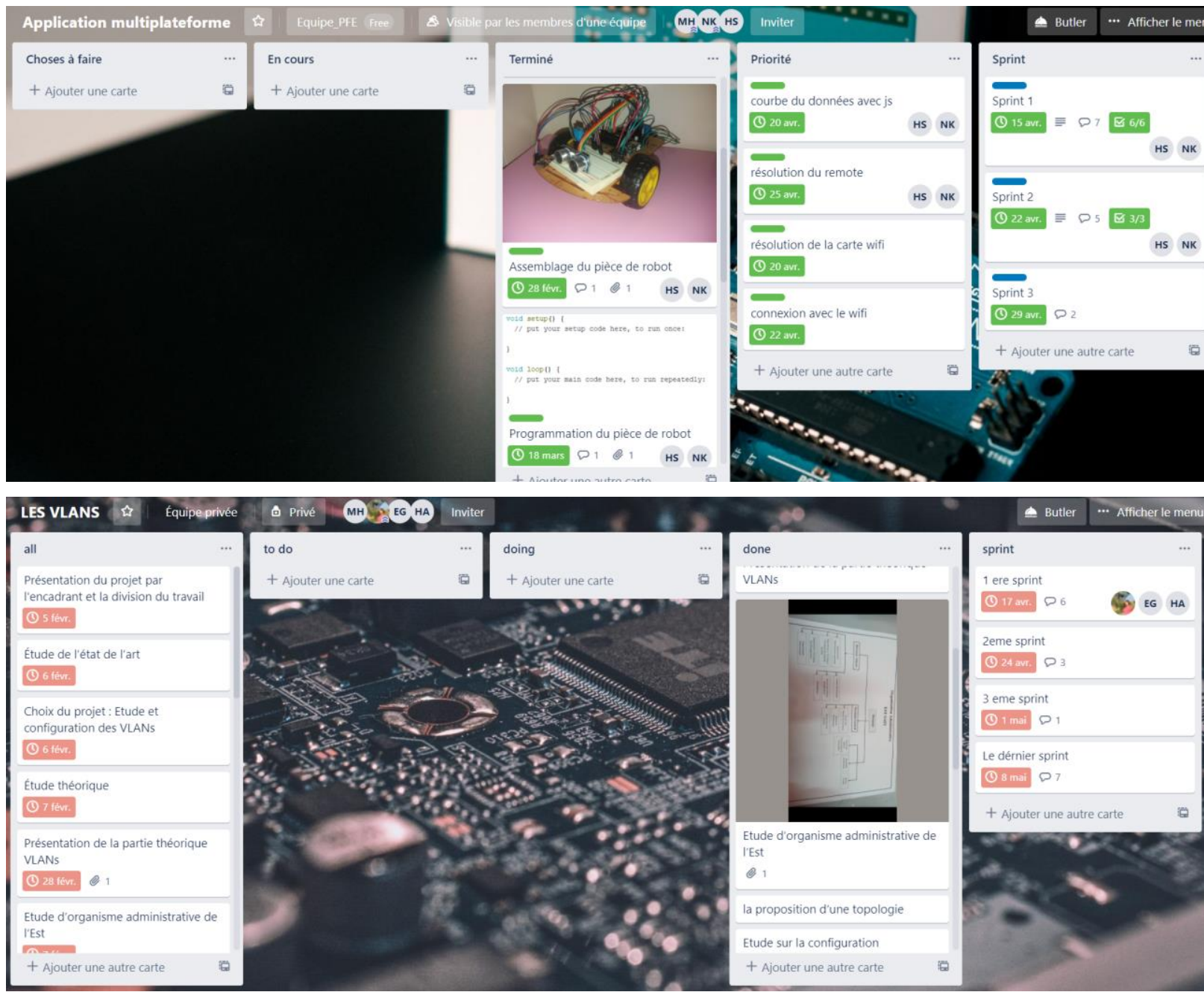

Figure 3 contains the respondents' answers in percentages for the survey items. The results show that the applied agile project management was considered to be very useful to complete their project by the majority of respondents (96\% between agree and strongly agree). Almost the same respondents think that this strategy would useful for their academic, personal or professional projects in the future. 
Figure 3: Survey results

1. Do you believe that the distribution of roles of Scrum Team are helpful for group dynamics and...

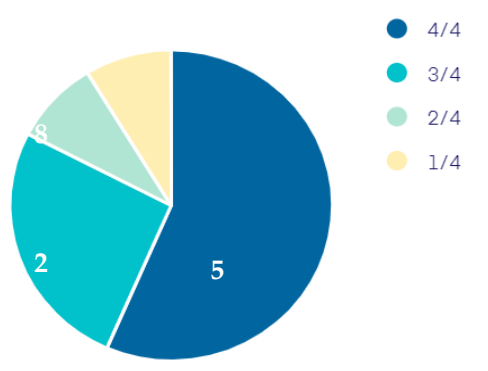

3. Do you believe that the agile methodology helped simplify teamwork organisation?

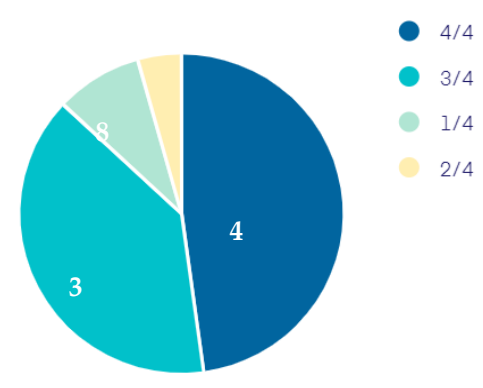

5. Do you think that Trello web based application helped tracking team project activities?

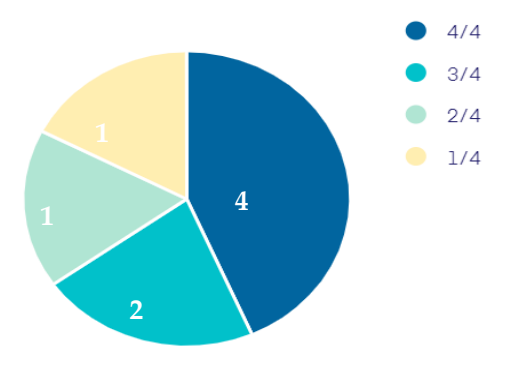

9. In your opinion, has the agile methodology been useful for completing the project?

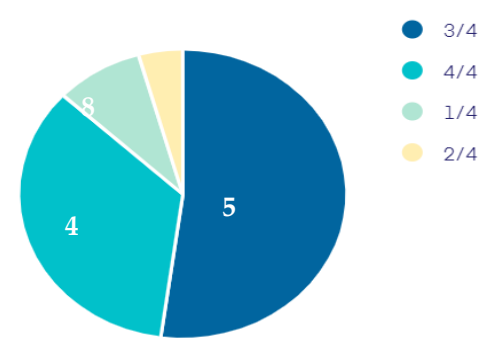

2. In your opinion, have the monitoring meetings been useful for work coordination and for...

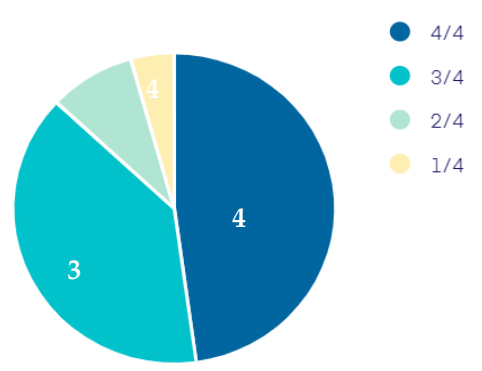

4. Do you think that Trello web based application helped to organize and centralize project data?

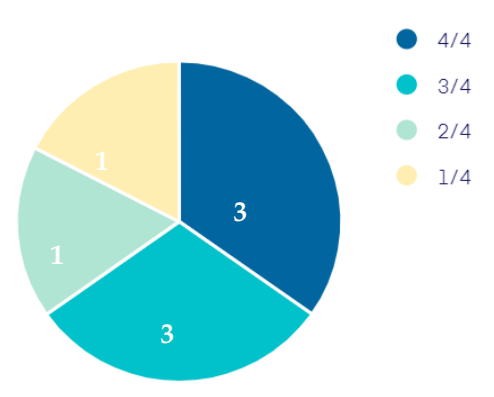

6. In your opinion, has the agile methodology been useful for monitoring the project progress?

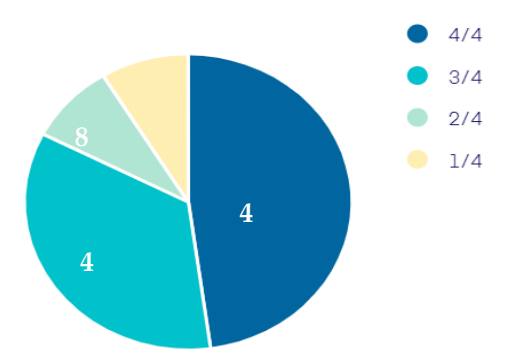

10. Do you believe that you will be able to transfer the agile methodology to other contexts in your life...

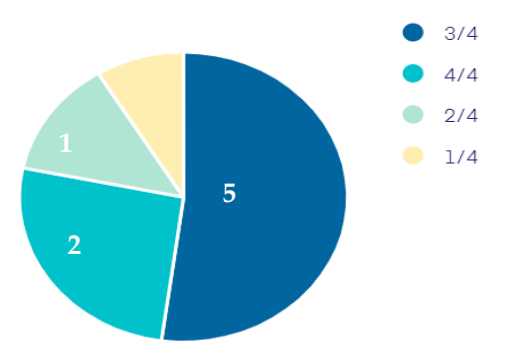

For items concerning communication and collaboration between project team members, the majority affirmed that the adopted method was helpful for group dynamic and distributing responsibilities, regular meetings were helpful for work coordination and globally the agile methodology simplified the teamwork organization. Indeed, clear definition of tasks and transparent attribution of roles and responsibilities to 
teamwork members increases group commitment and reduces conflicts due to unequal involvement. This well distribution of roles facilitate students' comprehension of the organizational model of their projects. Furthermore, the visualization tool of the agile strategy allows a synchronous communication and collaboration between team members in a shared space. In this regard, it helped assess group dynamic as it offers an objective information about students' involvement (meetings participation, task updates, comments...).

For items covering data centralization and project monitoring, significant number of respondents believe that agile project dashboard helped centralize project documentation and track teamwork real-time progress. In fact, working in cycles gives students as well as teachers a more predictable scenario of project progress. And using a visualization tool for this purpose by assigning a status and deadlines to tasks and uploading deliveries in the project workflow facilitates the project teamwork monitoring.

\section{CONCLUSION, LIMITATION AND FUTURE RESEARCH}

This study provides an experience report on the application of agile project management in an online higher education context, which has been required by the covid19 pandemic crisis. In summary, results reveal that the applied agile strategy presents interesting opportunities to enrich remote project management in an online educational context that differs from face-to-face education. Our initial experiment with undergraduate students proves that it helps overcoming the encountered issues concerning communication and collaboration between teamwork's members and the overall project tracking and monitoring.

Our study has almost similar findings as the results of previous works in the literature in terms of team working skills improvement and general performance of students on project management. We have also demonstrated that it is an impeccable solution allowing to overcome the constraints imposed by the pandemic in the context of the monitoring of educational projects. On the basis of these data and our observations, we can infer the following aspects:

- Using the agile method, students engage effectively as a team while overcoming team conflicts and enjoying their remote work.

- Students were more organized by having all of the project data on a centralized dashboard.

- It was easy and very practical for us as teachers to monitor the progress of students' projects remotely and to assess the performance and involvement of each in the final project.

As one of its main limitation, this study involved a small sample of students. Further investigation should be led with larger sample of students and supervisors from diverse courses in order to determine the transferability to other disciplines and obtain more rigorous evaluation patterns.

\section{REFERENCES}

Almathkoori,H., Bouchareb,R. \& Flores-Tena,M.J. (2020). Physical activity practitioners: Reducing infection with coronavirus. International Journal of Educational Research Review,5(4),335-342.

Bass, R. B., Pejcinovic, B., \& Grant, J. (2016). Applying Scrum project management in ECE curriculum. Proceedings - Frontiers in Education Conference, FIE, 2016-November. https://doi.org/10.1109/FIE.2016.7757568.

Camélia Docquin. (2020, June 29). What the Covid-19 crisis can teach us about Project Management? I Sciforma. https://www.sciforma.com/blog/what-covid-19-crisis-can-teach-us-about-project-management.

Hidalgo, E. S. (2019). Adapting the scrum framework for agile project management in science: case study of a distributed research initiative. Heliyon, 5(3), e01447. https://doi.org/10.1016/j.heliyon.2019.e01447.

Kropp, M., Meier, A., \& Biddle, R. (2016). Teaching agile collaboration skills in the classroom. Proceedings 2016 IEEE 29th Conference on Software Engineering Education and Training, CSEEandT 2016, 118-127. https://doi.org/10.1109/CSEET.2016.27.

Makhzoum,V. \& Jabbour,M. (2020). Critical thinking and it is role in facing Coronavirus. International Journal of Educational Research Review,5(4),389-406. 
Maria, R. E., Junior, L. A. R., Vasconcelos, L. E. G. De, Pinto, A. F. M., Tsoucamoto, P. T., Silva, H. N. A., Lastori, A., Cunha, D. A. M., \& Dias, L. A. V. (2015). Applying Scrum in an interdisciplinary project using big data, internet of things, and credit cards. Proceedings - 12th International Conference on Information Technology: New Generations, ITNG 2015, 67-72. https://doi.org/10.1109/ITNG.2015.17.

Miller, M., \& Hadwin, A. (2015). Scripting and awareness tools for regulating collaborative learning: Changing the landscape of support in CSCL. Computers in Human Behavior, 52, 573-588. https://doi.org/10.1016/j.chb.2015.01.050.

Naik, N., \& Jenkins, P. (2019). Relax, it's a game: Utilising gamification in learning agile scrum software development. IEEE Conference on Computatonal Intelligence and Games, CIG, 2019-August. https://doi.org/10.1109/CIG.2019.8848104.

Noguera, I., Guerrero-Roldán, A. E., \& Masó, R. (2018). Collaborative agile learning in online environments: Strategies for improving team regulation and project management. Computers and Education, 116, 110129. https://doi.org/10.1016/j.compedu.2017.09.008.

Parsons, D., Thorn, R., Inkila, M., \& MacCallum, K. (2019). Using Trello to Support Agile and Lean Learning with Scrum and Kanban in Teacher Professional Development. Proceedings of 2018 IEEE International Conference on Teaching, Assessment, and Learning for Engineering, TALE 2018, 720-724. https://doi.org/10.1109/TALE.2018.8615399.

Rabbi,M.F., Smita,M.K. \& Mohammad,S. (2020). Using social networking sites as medium of instruction at tertiary education during Covid-19 situation in Bangladesh. International Journal of Educational Research Review,5(3),258-264. 